\title{
Structural details and composition of Trichomonas vaginalis lipophosphoglycan in relevance to the epithelial immune function
}

\author{
Bibhuti N. Singh • Gary R. Hayes • John J. Lucas • \\ Ulf Sommer • Nelly Viseux • Ekaterina Mirgorodskaya • \\ Radiana T. Trifonova - Rosaria Rita S. Sassi • \\ Catherine E. Costello • Raina N. Fichorova
}

Received: 1 April 2008 /Revised: 11 May 2008 / Accepted: 5 June 2008 / Published online: 6 July 2008

(C) The Author(s) 2008

\begin{abstract}
Trichomonas vaginalis causes the most common non-viral sexually transmitted infection linked to increased risk of premature birth, cervical cancer and HIV. This study defines molecular domains of the parasite surface glycoconjugate lipophosphoglycan (LPG) with distinct functions in the host immunoinflammatory response. The ceramide phospho-inositol glycan core (CPI-GC) released by mild acid had $\mathrm{Mr}$ of $\sim 8,700 \mathrm{Da}$ determined by MALDI-TOF MS. Rha, GlcN, Gal and Xyl and small amounts of GalN and Glc were found in CPI-GC. $N$-acetyllactosamine repeats were identified by endo- $\beta$-galactosidase treatment followed by MALDI-MS and MS/MS and capLC/ESI-MS/ MS analyses. Mild acid hydrolysis led to products rich in internal deoxyhexose residues. The CPI-GC induced chemokine production, NF- $\mathrm{KB}$ and extracellular signalregulated kinase (ERK)1/2 activation in human cervicovaginal epithelial cells, but neither the released saccharide components nor the lipid-devoid LPG showed these
\end{abstract}

B. N. Singh $\cdot$ G. R. Hayes $\cdot$ J. J. Lucas

Department of Biochemistry and Molecular Biology,

SUNY Upstate Medical University,

750 E Adams St, Syracuse, NY 13210, USA

U. Sommer $\cdot$ N. Viseux $\cdot$ E. Mirgorodskaya $\cdot$ C. E. Costello

Center for Biomedical Mass Spectrometry,

Boston University School of Medicine,

670 Albany St., Rm 511, Boston, MA 02118, USA

R. T. Trifonova $\cdot$ R. R. S. Sassi $\cdot$ R. N. Fichorova $(\square)$

Laboratory of Genital Tract Biology,

Department of Obstetrics, Gynecology and Reproductive Biology,

Brigham and Women's Hospital, Harvard Medical School,

221 Longwood Ave RF468, Boston, MA 02115, USA

e-mail: rfichorova@rics.bwh.harvard.edu activities. These results suggest a dominant role for CPI$\mathrm{GC}$ in the pathogenic epithelial response to trichomoniasis.

Keywords Trichomonad LPG · Mass spectrometry · Cytokines $\cdot \mathrm{NF}-\mathrm{kB} \cdot \mathrm{ERK} \cdot$ Vaginal mucosal immunity

\begin{tabular}{|c|c|}
\hline \multicolumn{2}{|l|}{ Abbreviations } \\
\hline CPI-GC & ceramide phospho-inositol glycan core \\
\hline DHB & 2,5-dihydroxy-benzoic acid \\
\hline ESI & electrospray ionization \\
\hline GPI & glycosylated phosphatidylinositol \\
\hline FACE & $\begin{array}{l}\text { fluorophore-assisted carbohydrate } \\
\text { electrophoresis }\end{array}$ \\
\hline FT MS & $\begin{array}{l}\text { Fourier transform ion cyclotron resonance } \\
\text { mass spectrometry }\end{array}$ \\
\hline HPAE-PAD & $\begin{array}{l}\text { high performance anion exchange } \\
\text { chromatography-pulsed amperometric } \\
\text { detector }\end{array}$ \\
\hline $\mathrm{LC}$ & liquid chromatography \\
\hline LPG & lipophosphoglycan \\
\hline LPS & lipopolysaccharide \\
\hline MALDI-TOF & matrix-assisted laser desorption ionization/ \\
\hline MS & time-of-flight mass spectrometry \\
\hline NMR & nuclear magnetic resonance \\
\hline PAS & periodic acid-Schiff staining \\
\hline PBS & phosphate-buffered saline \\
\hline PI-PLC & phosphatidylinositol-specific phospholipase-C \\
\hline PSD & post-source decay \\
\hline QoTOF & quadrupole orthogonal time-of-flight \\
\hline SORI-CID & $\begin{array}{l}\text { sustained off resonance irradiation- } \\
\text { collision-induced decomposition }\end{array}$ \\
\hline TFA & trifluoroacetic acid \\
\hline TV & Trichomonas vaginalis \\
\hline TF & Tritrichomonas foetus \\
\hline
\end{tabular}




\section{Introduction}

Trichomonas vaginalis is an extracellular parasitic protozoan that causes one of the most common non-viral sexually transmitted infections, human trichomoniasis. Each year, over 180 million people are infected worldwide, including 8-10 million Americans [1-4]. Around the globe, infection rates have been reported to be as high as $67 \%$ in Mongolia [5], more than $60 \%$ in Africa, and $40 \%$ in indigenous Australian women [6]. T. vaginalis adheres to and damages vaginal epithelial cells $[7,8]$ and lives in the vagina of women and the urethra of men. In men, the infection is usually asymptomatic and self-limiting, although there may be an irritating urethritis or prostatitis [9, 10]. In women, the infection causes a wide range of inflammatory symptoms and has major health, economic and social consequences including preterm delivery, low birth weight, transmission of the parasite to newborn girls during delivery, infertility, cervical cancer and enhanced transmission rate of HIV [1, 4, 11-13].

The $T$. vaginalis virulence factors responsible for the remarkable evasion of the host immunity and the severity of the pathologic inflammatory reaction in trichomoniasis remain elusive. Although women may develop specific antibodies to $T$. vaginalis antigens, the infections do not provide lasting immunity, and reinfection is common [1, 4]. Undefined phenotypic variations, release of proteases and other unknown factors have been attributed to the chronic nature and re-incidence of infections [1, 14], as well as the host inflammatory responses during infection $[15,16]$. In other parasitic protozoa, cell surface glycoconjugates, e.g., glycolipids, glycoproteins, and glycosylated phosphatidyl inositol (GPI) glycolipids have been implicated in cell adhesion, host cell invasion and evasion of host immune responses [17-20]. The importance of carbohydrate moieties in the pathogenesis of trichomoniasis is suggested by earlier studies showing that pretreatment of trichomonads with periodate abolishes the adhesion of parasites to their respective host cells [7, 21]. We isolated and partially characterized $T$. vaginalis lipophosphoglycan (LPG) and obtained evidence for its essential role in the parasite adherence and the proinflammatory activation of epithelial cells from all three distinct anatomic compartments of the lower human female genital tract-endocervix, ectocervix and vagina [22].

LPG is the most abundant glycosylated molecule in the pathogenic trichomonads $T$. vaginalis and Tritrichomonas foetus $\left(2-3 \times 10^{6}\right.$ copies/parasite). T. foetus causes bovine trichomoniasis; this represents the only animal model for human trichomoniasis. T. vaginalis and T. foetus LPGs are anchored on the cell surface via a phospho-inositol ceramide (CPI) [23, 24]. LPG contains mostly carbohydrate and the lipid component, and is devoid of any peptide [22,
24, 25]. To a certain extent, trichomonad LPGs are analogous to the LPGs from other parasites, but the $T$. vaginalis and $T$. foetus LPGs are clearly distinct from them in their monosaccharide compositions and other structural features $[22,26,27]$. Unlike the LPG from Leishmania (which has distinct promastigote and amastigote stages), the LPGs from trichomonads (which have only one stage) do not undergo structural modifications during parasite development. Furthermore, unlike the previously described GPI-anchored molecules, TV-LPG contains no mannose and our earlier data has suggested the presence of the phospho-inositol linked ceramide [23, 24] and poly- $N$-acetyllactosamine repeats (Gal $\beta 1-$ $4 \mathrm{GlcNAc}$ ) in the LPG molecule [22, 26]. We previously demonstrated that trichomonad LPGs are involved in the adhesion of parasites to their respective host cells in a species-specific manner, a behavior which may be related to the unique monosaccharide compositions of $T$. vaginalis and T. foetus LPGs [21, 22]. Bastida-Corcuera et al. [28] produced $T$. vaginalis mutants defective in LPG and showed that these mutants have reduced adherence and cytotoxicity to cervical epithelial cells, confirming our own biochemical observations [21, 22].

Along with the partial compositional characterization of T. vaginalis $\mathrm{LPG}$, we recently reported the first evidence for TV-LPG's role in triggering a selective and species-specific production of cytokines by human female genital tract epithelial cells [22]. Here we further define the biochemical nature of $T$. vaginalis LPG and determine the specific molecular domain required for triggering immunoinflammatory pathways in human vaginal and cervical epithelia.

\section{Materials and methods}

\section{Parasites and LPG}

T. vaginalis isolates (UR1) obtained from a symptomatic patient were cultured in Diamond's modified media $(\mathrm{pH}$ 6.0) with $10 \%$ heat-inactivated horse serum (HyClone Laboratory) at $37^{\circ} \mathrm{C}$, as reported earlier [7]. Parasites were harvested in late log phase $(24 \mathrm{~h})$ by centrifugation and washed twice with phosphate-buffered saline (PBS, $\mathrm{pH} 7.4$ ) and suspended in methanol/chloroform (1:2) followed by extraction of the LPG with solvent E [23]. LPGs from $T$. vaginalis and $T$. foetus were isolated and purified on an octyl-Sepharose column as previously described [23].

Generation of saccharides and ceramide phospho-inositol glycan core (CPI-GC) fractions of LPG

LPG was digested by various chemical and enzymatic treatments and the resultant sub-domains presented sche- 
matically in Fig. 1 were purified and characterized as described below.

Mild acid-released fractions LPG was hydrolyzed with $100 \mathrm{mM}$ TFA containing DTT $(1 \mathrm{mg} / \mathrm{mL})$ at $100^{\circ} \mathrm{C}$ for $3 \mathrm{~h}$, under a $\mathrm{N}_{2}$ atmosphere. The resultant sample was dried with 2-propanol and resuspended in a small volume of $0.1 \%$ TFA. The sample was placed on a C18 Sep-Pak ${ }^{\circledR}$ column (Waters Corp., Milford, MA, USA). Saccharides (outer branch) were eluted with $0.1 \%$ TFA and the CPI-GC was eluted sequentially with $30 \%, 50 \%$, and $70 \% n$-propanol. Aliquots from the outer branch saccharide fraction and the CPI-GC fraction were dried and later used to stimulate human cervicovaginal epithelial cells, as described below. Additional aliquots of the same fractions were dried and used for monosaccharide and MS analyses. SDS-PAGE followed by PAS staining was used to verify the release of the CPI-GC from LPG. For monosaccharide composition analysis, aliquots of the outer branch saccharide and CPI-GC fractions were hydrolyzed with $4 \mathrm{M}$ TFA at $125^{\circ} \mathrm{C}$ for $1 \mathrm{~h}$ and the monosaccharides were separated and quantified on a PA1 column (Dionex Corp., Sunnyvale, CA, USA) by HPAE-PAD as reported earlier [22]. The CPI-GC fraction released by TFA treatment is referred to later as "native" CPI-GC in contrast to "post-enzymatic" CPI-GC derived by endo- $\beta$-galactosidase digestion of "native" CPI-GC.

Glycosidase treatment "Native" CPI-GC was treated with $\beta$-galactosidase (Jack bean), $\beta$ - $N$-acetylhexosaminidase
(Jack bean), and endo- $\beta$-galactosidase (Bacteroides fragilis) which were purchased from Oxford Glyco Systems (Oxford, UK). In a few experiments, endo- $\beta$-galactosidase (Escherichia freundii) was also obtained from Seikagaku Corp. (Tokyo, Japan; Associates of Cape Cod, Inc., East Falmouth, MA, USA). The incubation conditions recommended by the manufacturers were employed in a total volume of $0.2 \mathrm{~mL}$. The released saccharide(s) and the "postenzymatic" CPI-GC (glycan lipid core) were separated on a C18 Sep-Pak as described above. The saccharides were labeled with the fluorophore, 8-aminonapthalene-1,3, 6-trisulfonic acid (ANTS), and subjected to Glyko-FACE analysis for sequencing, as described by the manufacturer. Selected individual bands were cut and purified by elution from the gel slices in $\mathrm{H}_{2} \mathrm{O}$ and re-analyzed. The monosaccharide compositions of the released fractions were quantified by HPAE-PAD. Individual saccharide fractions were further analyzed by MALDI-TOF MS, MALDI-FTMS and $\mathrm{LC} / \mathrm{MS} / \mathrm{MS}$.

The endo- $\beta$-galactosidase released saccharide fraction and the post-enzymatic CPI-GC fraction were used to stimulate human cervicovaginal epithelial cells as described below.

The following two enzymes were used to examine the release of Rha or Xyl from native LPG, CPI-GC and the mild acid released saccharide fractions: (1) rhamnosidase B from Bacillus $\mathrm{Sp}$ (specific for releasing terminal $\alpha-\mathrm{L}(+)$ Rha from rhamnosyl disaccharides) obtained from Dr. K. Murata (Kyoto University, Japan) [29]; and (2) $\beta$-Dxylosidase from Selenomonas ruminatium (which catalyzes
Fig. 1 Schematic of T. vaginalis LPG showing the major breakdown products e.g. outer saccharide branch and ceramide phospho-inositol glycan core (CPI-GC) cleaved by mild TFA hydrolysis

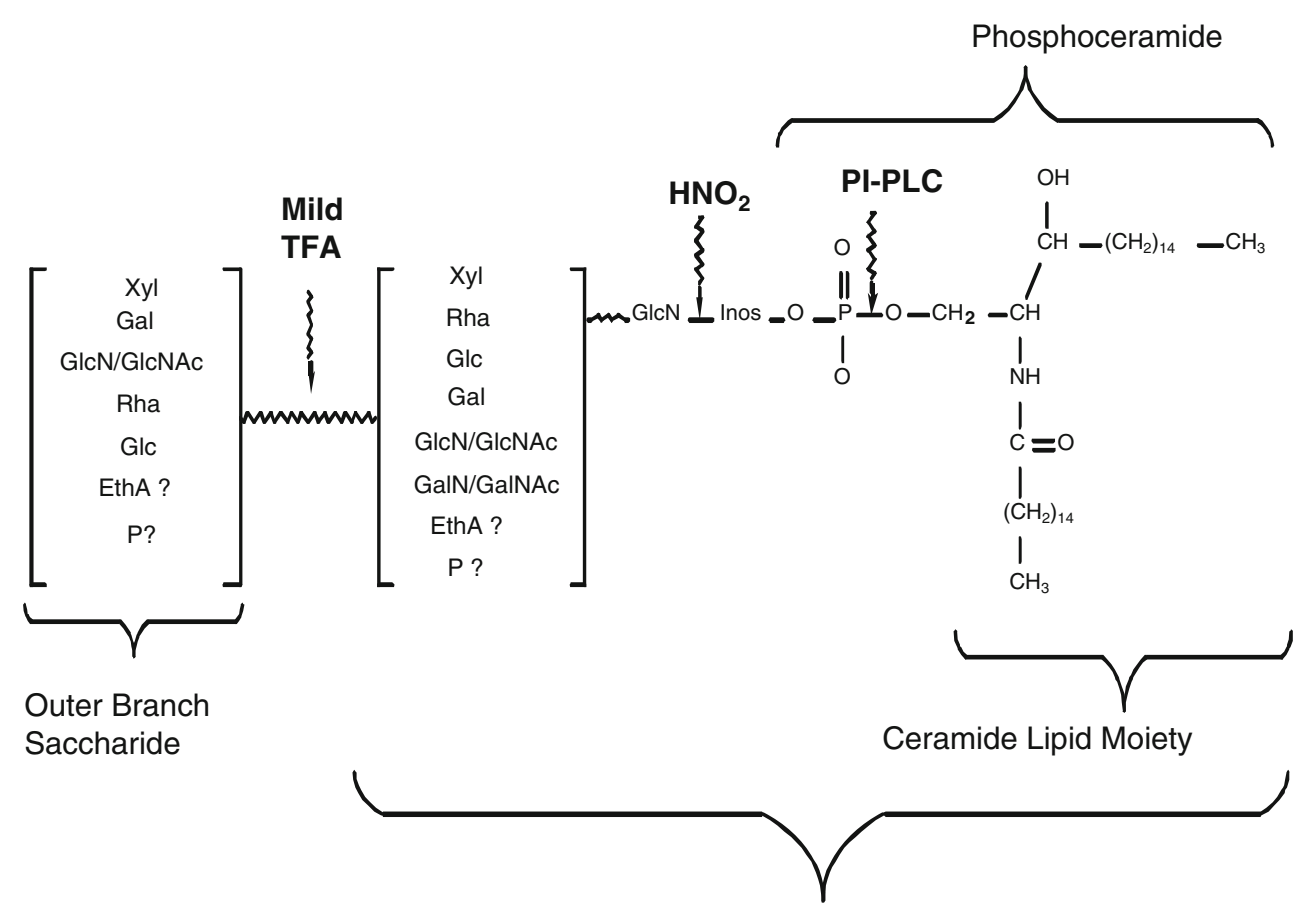

Ceramide Phospho-Inositol Glycan Core (CPI-GC) 
the hydrolysis of the $\beta 1-4$ linkage of long polymers of xylose) kindly provided by Dr. D. B. Jordan (USDA, ARS, IL, USA) [30].

PI-PLC treatment of LPG To separate the lipid moiety from the oligosaccharide-inositol-phosphate core (saccharide-I-P) as previously shown $[23,24]$, intact LPG was treated with PI-PLC from Bacillus thuringiensis (obtained from PROzyme Corp., San Leandro, CA, USA) per the manufacturer's instructions for $20 \mathrm{~h}$ at $37^{\circ} \mathrm{C}$. After the reaction was stopped with hot ethanol, the solution (which contained the complete non-lipoid saccharide) was dried and placed on C18 Sep-Pak and eluted with $0.1 \%$ TFA. The eluant which contained the oligosaccharide-I-P, i.e., the LPG devoid of the ceramide moiety, was collected and dried and was later subjected to functional analysis in stimulation of cervicovaginal epithelial cells, as described below.

Periodate treatment Intact LPG was treated with periodate $(10 \mathrm{mM})$ in sodium acetate buffer $\mathrm{pH} 4.5$ for $4 \mathrm{~h}$, as described [7, 21] and the reaction was stopped by the addition of excess glycerol to destroy unreacted periodate. The reaction mixture was dried and dissolved in $0.1 \%$ TFA. It was further purified on a C18 Sep-Pak column and the lipid-containing fraction that was eluted with $n$-propanol $(30-70 \%)$ was collected and examined to determine its effect in upregulation of cytokines in our experimental human cell model.

\section{Mass spectrometry}

$C P I-G C$ The mass of the native CPI-GC was determined by matrix-assisted laser desorption/ionization time-of-flight mass spectrometry (MALDI-TOF MS) on a Reflex IV mass spectrometer (Bruker Corp., Billerica, MA, USA), using a UV laser (337 nm, 3-ns pulse width) and 2,5-dihydroxybenzoic acid as the matrix for analysis of samples deposited on a stainless steel target. The data were acquired using Flexcontrol, and were displayed using MoverZ freeware (Proteometrics, LLC; now within Genomic Solutions, Ann Arbor, MI, USA).

Glycans The sugars released by mild acid or enzymes, were analyzed (without derivatization) by MALDI-TOF MS and PSD of the positive ions on a Vision 2000 reflectron TOF MS [Finnigan Corp. (now Thermo-Fisher Scientific), Bremen, Germany] [31] and also by MALDI-FT MS with SORI-CID on an Ion-Spec system (IonSpec Corp., Irvine, CA, USA; now Varian FTMS, Lake Forest, CA, USA), with an external MALDI source and a 7-T actively shielded magnet. For both types of MALDI-MS analysis, the matrix was 2,5-DHB. FTMS data are displayed using the BUDA open source software developed by P. B. O'Connor at Boston University Center for Biomedical Mass Spectrometry and available on its websites (www. busm.bu.edu/msr and www.busm.bu.edu/cardiovascularpro teomics).

To increase sensitivity and provide more informative fragmentation, the released glycans were permethylated $[31,32]$ and further characterized by MALDI-TOF MS, and MALDI-FTMS. For both types of MALDI analysis of the permethylated glycans, 2,5-DHB was used as the matrix. In later experiments, nanospray MS/MS, or capLC-MS/MS was employed for samples that were reduced with sodium borohydride (to avoid chromatographic separation into two anomeric forms) then purified with a HyperSEP Hypercarb column (Thermo-Fisher Scientific, Waltham, MA, USA) and permethylated. These derivatized glycans were analyzed online with a QStar Pulsar $i$ QoTOF (quadrupole orthogonal time-of-flight) MS (Applied Biosystems/Sciex, Toronto, ON, Canada), using protocols we have described recently [32]. Samples were introduced via self-pulled glass-tips, or Thermo Hypersil-Keystone porous graphite chromatography (PGC) columns $(2.1 \times 50 \mathrm{~mm})$ on a turbo spray ion source, and QAnalyst software [32]. Tandem MS experiments were performed on $[\mathrm{M}+\mathrm{H}]^{+}$and $[\mathrm{M}+\mathrm{Na}]^{+}$ ions; several runs were repeated, excluding values up to $\mathrm{m} / \mathrm{z}$ 900 from independent data acquisition to avoid solvent clusters. For LC/MS experiments, the flow rate through the analytical column was maintained at $30 \mu \mathrm{L} / \mathrm{min}$ through stepwise gradients of different lengths, ranging from $30 \% \mathrm{~B}$ to $100 \%$ B (A: $0.1 \%$ formic acid in water; B: $0.1 \%$ formic acid in acetonitrile/isopropanol 1:1) and an after-column syringe feed of $2 \mathrm{~mL} / \mathrm{min}$ of $5 \%$ formic acid was employed. MS/MS spectra were interpreted using QAnalyst software and a self-made calculation table for reduced and permethylated glycans.

Epithelial cell lines and treatment protocols

Well established immortalized human vaginal, ectocervical and endocervical epithelial cell lines [22, 33-40], were grown in keratinocyte serum-free medium supplemented with $50 \mu \mathrm{g} / \mathrm{mL}$ bovine pituitary extract, $0.1 \mathrm{ng} / \mathrm{mL}$ epidermal growth factor, penicillin/streptomycin, and $\mathrm{CaCl}_{2}$ as described [33]. All cell culture reagents were purchased from Invitrogen (Carlsbad, CA, USA). The cell lines have been derived from normal endocervical, ectocervical, and vaginal epithelium and closely represent the phenotypes of their tissues of origin [33]. These cell lines produce distinctive repertoires of immunological mediators under basal, as well as stimulated conditions, in the absence of TLR4 expression [37] and maintain closely the phenotypic characteristics of their tissues of origin [40]. They have 
been widely employed as in vitro models for studying cervical/vaginal physiology and infection [28, 34, 37-39, 41-44].

Confluent cell monolayers in 96-well plates were exposed to escalating doses of LPG, equivalent doses of LPG sub-domain fractions and live $T$. vaginalis for indicated period of time. Recombinant human IL-1 $\beta$ (R\&D Systems, Minneapolis, MN, USA) served as a positive control for epithelial proinflammatory activation. Nontoxic experimental doses of LPG were selected based on MTT viability assays and ranged from 500 to $15 \mu \mathrm{g} / \mathrm{mL}$. These doses were equivalent to $2.5 \times 10^{7}-0.8 \times 10^{6}$ parasites $/ \mathrm{mL}$, or about $10^{-1}$ parasites/epithelial cell in our experimental model, which approximates parasite load during trichomonad infection [22]. The concentration of each LPG fraction was normalized based on the known amount of LPG used for the isolation of this fraction. At the end of each stimulation period, cell culture supernatants were collected for cytokines, and the cells were used for MTT viability assay (Promega, Madison, WI, USA) as described in detail elsewhere [22] or were lysed for total protein assessment by BCA assay (Pierce, Rockford, IL, USA) and phosphoprotein analysis.

\section{Endotoxin measurement}

Endotoxin contamination of LPG and LPG fractions was ruled out using the EndoSafe Test System (Charles River Laboratories, Charleston, SC, USA) based on the Limulus Amoebocyte Lysate test [45] with sensitivity $<0.05 \mathrm{EU} / \mathrm{mL}$. A negative control and the recovery of a known amount of endotoxin spike are inherent in each sample testing in this system. Each sample was tested in quadruplicate with a coefficient of variation $<10 \%$.

Measurement of inflammatory mediators and phosphoproteins

Electrochemiluminescence (ECL) immunoassays and Imager 2400 (both from Meso Scale Discovery, Gaithersburg, MD, USA) determinations were used to measure IL-8 in cell culture supernatants and phosphoproteins in cell lysates, as previously described [22, 46]. For IL-8 analysis, epithelial cells were stimulated for $24 \mathrm{~h}$. For protein phosphorylation analysis, epithelial cells were stimulated for 30-90 $\mathrm{min}$, then rinsed with ice-cold PBS containing $1 \mathrm{mM} \mathrm{Na}_{3} \mathrm{VO}_{4}$ (Sigma, St. Louis, MO, USA) and lysed in $20 \mathrm{mM}$ Tris lysis buffer $\left(100 \mu \mathrm{L}\right.$ lysate per $10^{5}$ cells $)$, containing the phosphatase inhibitors $2 \mathrm{mM}$ PMSF and 0.01M NaF (Sigma) and Roche protease inhibitor cocktail (Fisher). The lysates were normalized to total protein concentration measured by BCA assay prior to analysis for phospho (p) extracellular signal-regulated ERK1/2 (Thr/
Tyr: 202/204; 185/187), pNF-kB/p65 (Ser538) and pMEK (MAPK/ERK) 1 and 2 (Ser217/221).

Activation of nuclear factor (NF)- $\mathrm{kB}$

The endocervical epithelial cell line End1/E6E7 was stably transfected with $\mathrm{pHTS}-\mathrm{NF} \kappa \mathrm{B}$ firefly luciferase reporter vector (Biomyx Technology, San Diego, CA, USA) using the genejuice transfection method [22] and hygromycin selection (Biomyx). The reporter cell line was seeded at $1 \times 10^{5}$ cells/ $\mathrm{mL}$ in 96-well plates and treated as described above. At the end of each stimulation period, cells were washed with PBS, lysed in Glo lysis buffer $0.1 \mathrm{~mL} /$ well and luciferase activity was measured using the Bright-Glo Luciferase Assay System per the manufacturer's instructions (Promega). The luminescence signal was read using Victor2 1420 multilabel microplate counter with Wallac software 2.01 (Perkin Elmer Life Sciences, Waltham, MA, USA).

Statistical analysis

One-way ANOVA with Dunnett's Bonferroni's multiple comparison tests or $t$-test analysis was performed using GraphPad Prism 4 (GraphPad Software, San Diego, CA, USA). $P$ values $<0.05$ were considered significant.

\section{Results}

Structural features of the LPG fragment

Previous data indicated the presence of terminal $\beta 1-4$-linked Gal residue(s) [47] in the T. vaginalis LPG structure, based on lectin RCA-1 binding to intact LPG [47]. Because of the complexity of LPG, its polydisperse nature and the unusual monosaccharide compositions [22], we designed a strategy to separate outer-carbohydrate and glycan-lipid subdomains to further study their composition and functional importance. Figure 1 shows a schematic summary of current knowledge of the complex LPG molecule, representing the generation of various fragments and their compositions.

The fraction referred to as the outer branch in Fig. 1 was released by mild acid treatment, as reported for Leishmania LPGs [17-19]. The nature of linkage between the outer branch saccharide fraction and the CPI-GC that is cleaved by mild TFA is not known at this point. So far, the hydrolysis observed upon treatment with mild acid, indicates that phosphate linkage(s) connect the CPI-GC core and the TFA released fractions; the possible presence of other types of linkages is still under investigation. Glyko-FACE analysis of this outer-branch fraction revealed several saccharide fragments equivalent to a size range of 2 to more than 20 standard glucose units (data not shown). 
Fig. 2 FACE analysis and predicted structure of endo- $\beta$-galactosidase digest of T. vaginalis $\mathrm{LPG}$. Lane 1 - total digest; lane 8-standard glucose oligomers. Bands $B$ and $A$ (marked with arrows) from lane $l$ were eluted and further digested with exoglycosidases shown in lanes 2-4 (band $B$ ) and 5-7 (band $A$ )

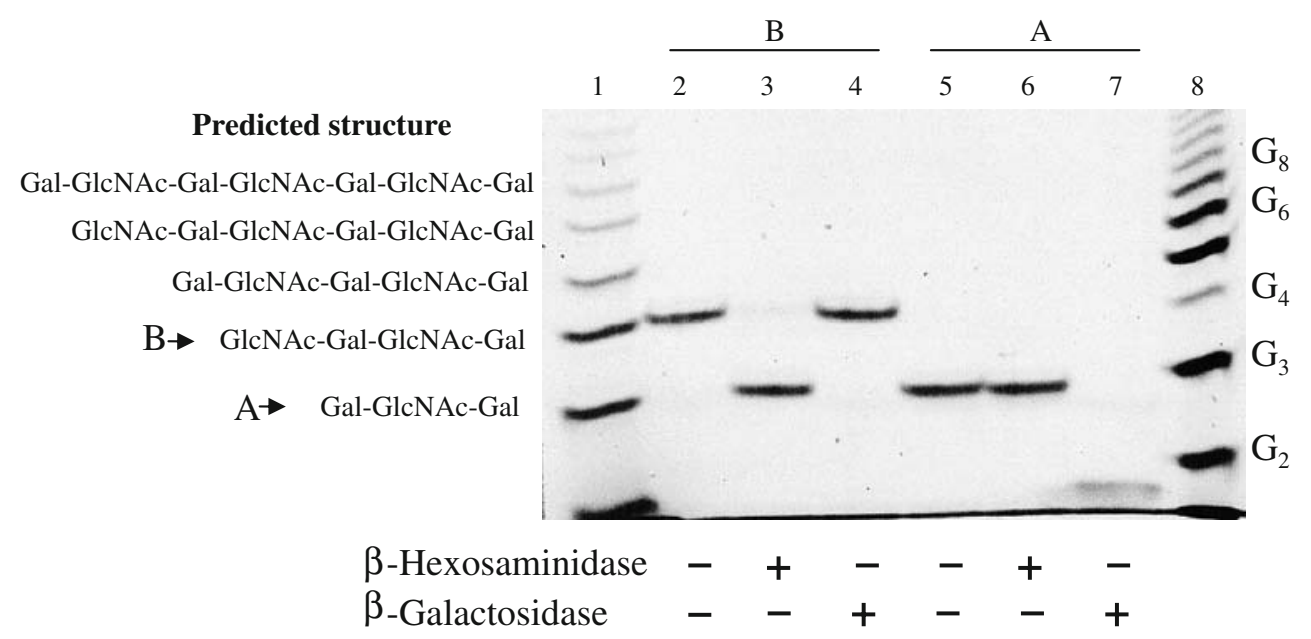

indicated that other oligosaccharides were rich in $\mathrm{dHex}$ (likely Rha based on monosaccharide analysis). Assignments for additional ions analyzed by MS/MS are underway.

The MALDI-TOF mass spectrum of the endo- $\beta$-galactosidase released glycans (Fig. 3a) had peaks at $\mathrm{m} / \mathrm{z} 406$, $568,771,933,1,136$ corresponding to the $[\mathrm{M}+\mathrm{Na}]^{+}$of HexHexNAc, HexHexNAcHex, (HexNAcHex $)_{2}$, (HexHex$\mathrm{NAc})_{2} \mathrm{Hex}$ and higher members of the series. The sequences of the glycan residues could be determined from the post-source decay spectra (e.g., Fig. 3b). Post-source decay results in only glycosidic cleavages, and therefore the order of the residues can be determined, but information on the linkage sites is not available. Treatment with $\beta-N$-acetyl hexosaminidase changed the MALDI mass spectrum shown in the top panel to a simpler series (Fig. 3c) having peaks at $365-\mathrm{u}$ intervals that correspond to HexHexNAc (likely $\mathrm{N}$-acetyllactosamine multimers), at $\mathrm{m} / \mathrm{z} 538,933,1,298$, etc. The presence of glycan regions having extended $\mathrm{N}$-acetyllactosamine repeats was later confirmed by nanospray MS/MS and capLC/MS/MS analyses of samples that had been subjected to reduction and permethylation. (The glycans were reduced before permethylation to avoid the peak splitting that would be introduced by resolution of $\alpha$ - and $\beta$-anomers during chromatographic separations.) Examples of the tandem mass spectra acquired during the LC/MS analysis of the reduced and permethylated glycans released by treatment of the intact LPG with endo- $\beta$ galactosidase are provided in Fig. 4. Figure 4a shows the CID MS/MS spectrum obtained for the glycan with [M + $\mathrm{Na}]^{+} \mathrm{m} / z 738.8$ and Fig. 4b, the glycan with $[\mathrm{M}+\mathrm{Na}]^{+} \mathrm{m} / \mathrm{z}$ 1,187.6. In contrast to PSD, CID-MS/MS produces some cross-ring cleavages and thus furnishes information on the linkages [48]. In the tandem mass spectrum shown in Fig. 4 , the ${ }^{3,5} \mathrm{~A}_{2}$ and ${ }^{3,5} \mathrm{~A}_{4}$ ions $\left(\mathrm{B}_{1}+88\right.$ and $\mathrm{B}_{3}+88$, respectively) indicate Hex1-4HexNAc linkages, while the absence of such an indicating ion suggests the presence of 1-3 linkages between HexNAc and Hex. 

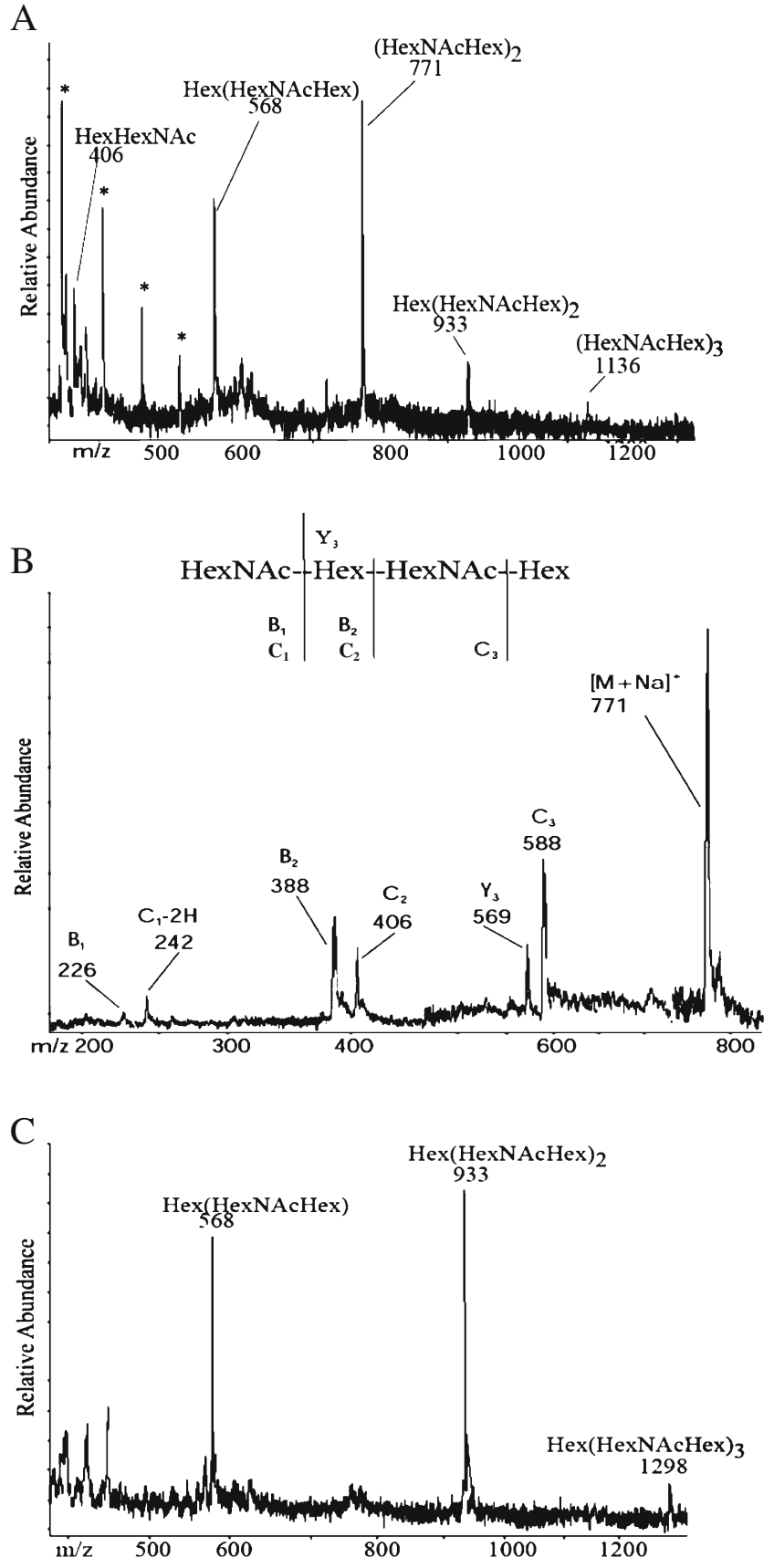

Fig. 3 a MALDI-TOF mass spectrum of the glycans released from TV LPG by endo- $\beta$-galactosidase. b PSD spectrum of the $[\mathrm{M}+\mathrm{Na}]^{+}$ $\mathrm{m} / \mathrm{z} 771$ in the spectrum shown above. All fragments except some of the peak centered at $m / z 588$ contain sodium. This peak likely contains contributions from the $\mathrm{B}_{3}(\mathrm{Na})$ fragment at $\mathrm{m} / \mathrm{z} 587$ and a $\mathrm{C}_{3}(\mathrm{H})$ fragment at $m / z$ 591. c MALDI-TOF mass spectrum of the glycans released from TV-LPG by endo- $\beta$-galactosidase, after subsequent treatment with hexosaminidase

In addition to the poly- $N$-acetyllactosamine regions, other segments of the LPG glycan structure contain few amino-sugars but have multiple internal deoxyhexose residues (most likely rhamnose, based upon HPAE-PAD analysis). The compositions of the various components observed in the MALDI-FTMS spectrum of the native LPG glycans, present in such an acid-released fraction, are assigned in Table 1. MALDI-FTMS SORI-CID analysis of these LPG-derived oligosaccharides obtained after mild $(100 \mathrm{mM})$ TFA hydrolysis indicated the presence of carbohydrates with a high content of deoxyhexose residues (Table 1). A typical tandem MS spectrum, obtained for $[\mathrm{M}+\mathrm{Na}]^{+} \mathrm{m} / z$ 960, is shown in Fig. 5. This spectrum is consistent with the carbohydrate composition proposed on the basis of the accurate mass measurement given in Table 1, that assigns the peak at $\mathrm{m} / \mathrm{z} 960.3578$ to $\mathrm{HexNAc}_{1} \mathrm{dHex}_{4}$ Pent $_{1}$ (calc. $[\mathrm{M}+\mathrm{Na}]^{+} \mathrm{m} / z$ 960.3536). From the observed fragments (Fig. 5) it is possible to conclude that parallel losses of Pent(Xyl), HexNAc and $\mathrm{dHex}(\mathrm{Rha})$ are indicative of a branched structure and deoxyhexose residues are likely adjacent to one another. Loss of $74 \mathrm{u}$ likely results from ${ }^{3,5} \mathrm{X}$-type cleavage of a HexNAc (or similar cleavage within a Pent residue). Although there remains some ambiguity because of the redundant compositions of fragments from candidate structures, it is clear that extensive deoxyhexose residues are present in the molecule. While it is possible that rearrangements occur during fragmentation of native oligosaccharides, it seems likely that isomeric structures are present. Additional $\mathrm{MS}^{\mathrm{n}}$ experiments, as well as NMR analyses, will be required to fully define all the potential structures.

Structural nature of the CPI-glycan core domain

Mild acid treatment also released the native CPI-GC core domain, which was isolated, treated and analysed as described in "Materials and methods". As elaborated below, the native and the endo- $\beta$-galactosidase treated CPI-GC moieties were largely responsible for chemokine production in human genital tract epithelial cells.

The native CPI-GC domain showed a heterogeneous band around $10-20 \mathrm{kDa}$ when analyzed by SDS-PAGE analysis and PAS staining [22]. When analyzed by MALDI-TOF MS, the $\mathrm{m} / \mathrm{z} 3,000-25,000$ region of the mass spectrum showed only a single high mass peak centered at $\mathrm{m} / \mathrm{z}$ 8,700 (Fig. 6). Compositional analysis of CPI-GC by HPAE-PAD showed the presence of significant amounts of Rha (25-30\%), GlcN (38-43\%), Gal (22-27\%), Xyl (4-8\%) and small amounts of GalN ( $1 \%$ or less) and Glc $(1-2 \%)$.

The monosaccharide compositional analysis of the entire CPI-GC fraction revealed large amounts of Gal, GlcN and Rha, further suggesting the presence of lactosamine types of saccharides in the CPI-GC molecule and the presence of Rha residues outside of the lactosamine repeats. This is consistent with the mass spectrometry data shown above. Xylose was also present in each of these fractions. In 
Fig. 4 Quadrupole orthogonal TOF CID MS/MS spectra obtained during a nanospray and b capLC-nanospray MS analysis of TV LPG-derived glycans with a $[\mathrm{M}+\mathrm{Na}]^{+} m / z$ 738.8, b $[\mathrm{M}+\mathrm{Na}]^{+} m / z$ 1,187.6. Putative structures of the $[\mathrm{M}+\mathrm{Na}]^{+}$ions are shown for these major components from $T$. vaginalis $\mathrm{LPG}$ that were analyzed after release by endo- $\beta$-galactosidase or mild acid hydrolysis, reduction and permethylation. The component whose spectrum is shown in a was generated by both enzymatic and acid release; the component in $\mathbf{b}$ appeared in only the acid-released fractions
A
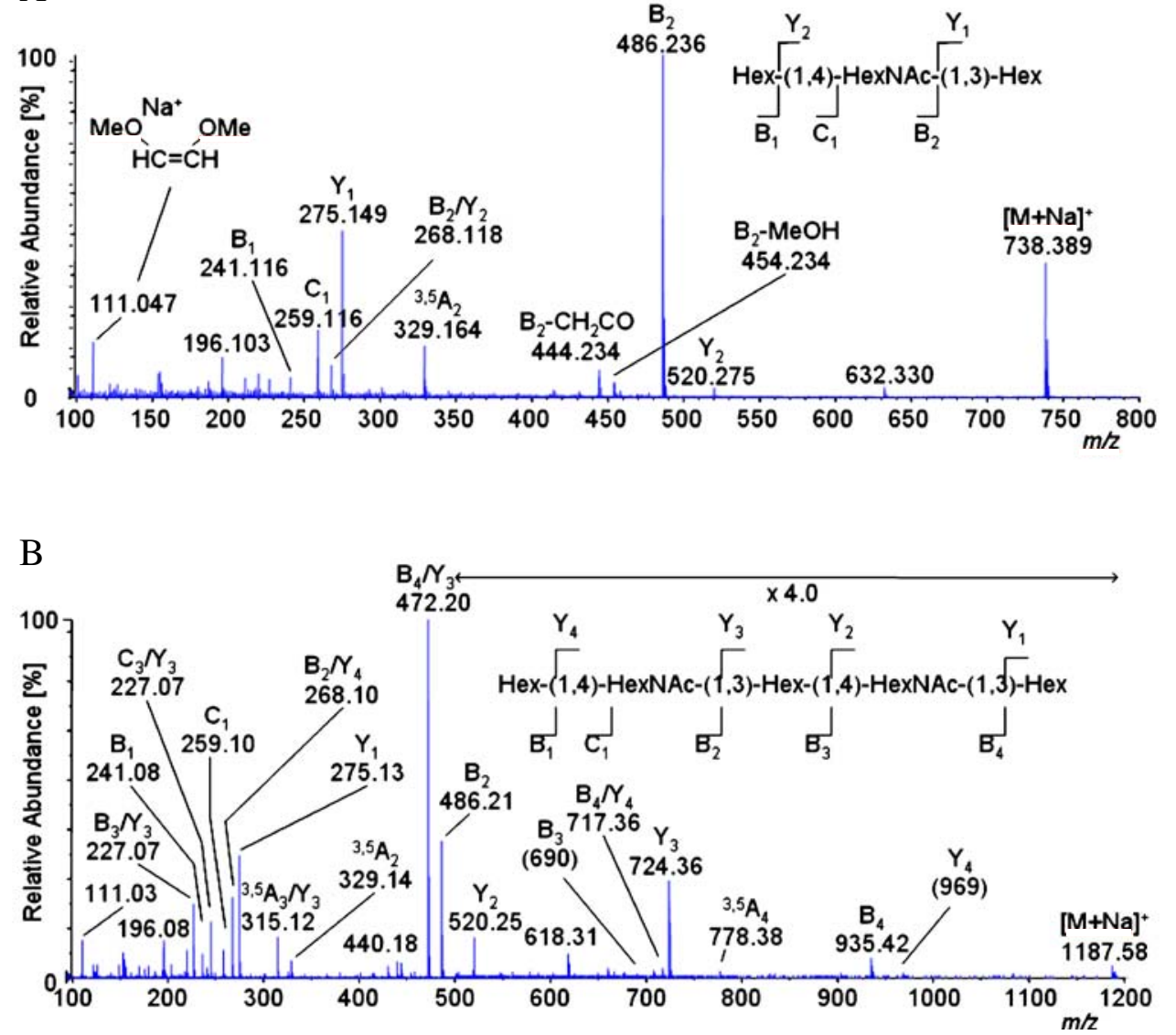

contrast, treatment with $\beta$-galactosidase, $N$-acetyl- $\beta$-hexosaminidase, rhamnosidase, and xylosidase failed to release any monosaccharides from native CPI-GC. After the native CPI-GC fraction was treated with endo- $\beta$-galactosidase, the released products were separated by C18-SepPak chroma- tography into a saccharide fraction and post-enzymatic CPIGC. The released saccharide fraction was analyzed by Glyko-FACE (Fig. 7). The saccharides ranged in size from 2-6 Glc units, suggesting the presence of $N$-acetyllactosamine repeats; similar to the results obtained above (Fig. 2).

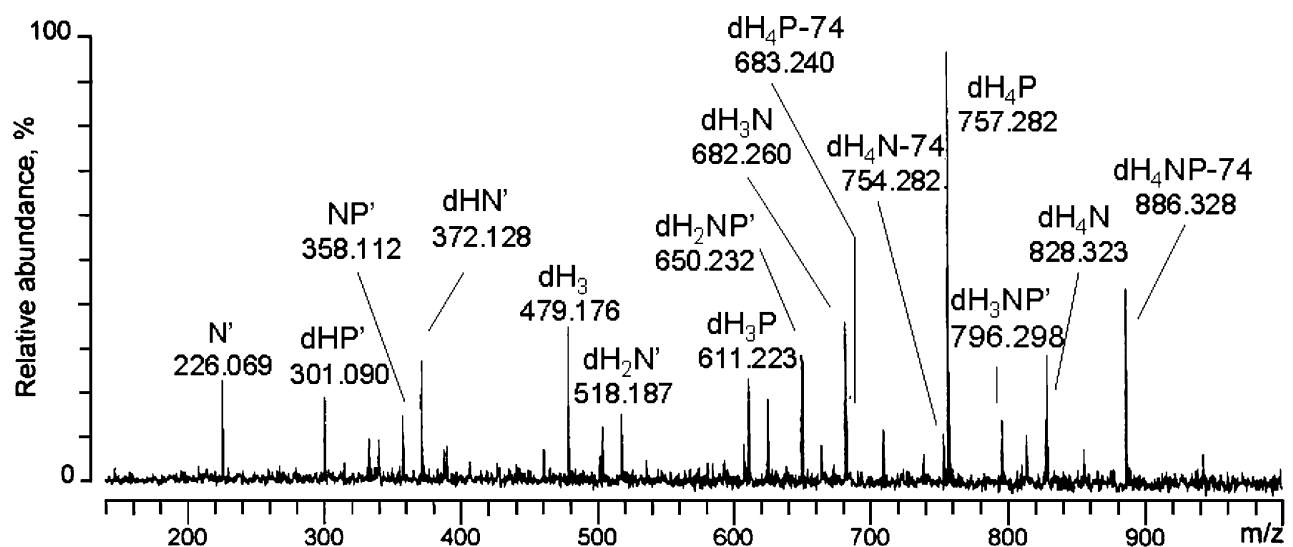

Fig. 5 SORI-CID mass spectrum obtained for the $[\mathrm{M}+\mathrm{Na}]^{+} \mathrm{m} / z 960$ in the MALDI-FTMS spectrum of oligosaccharides that were released from TV LPG by mild acid hydrolysis (outer branch saccharide). Compositions are indicated as $d H$, deoxyhexose; $N, N$-acetylhexosamine; $P$, pentose. Ions marked with an apostrophe (') are B- (or Z)- type ions, the rest are Y- (or C)-type ions; loss of $74 \mathrm{u}$ most likely originates through elimination of $\mathrm{CHOHCHCH}_{2} \mathrm{OH}$ from a nonreducing HexNAc (or Pent) terminus of the intact glycan or cleavage of an internal HexNAc residue that has 1,4-linkage, to form the ${ }^{3,5} \mathrm{X}_{\mathrm{n}}$-series. Low $m / z$ ions are internal ions. All ions contain $\mathrm{Na}$ 
Table 1 FTMS analysis of native TV-LPG glycans from an acid-released fraction
${ }^{\text {a }}$ The composition of $\mathrm{m} / \mathrm{z}$ 960.3578 was confirmed by the SORI-CID MS/MS analysis shown in Fig. 5

\begin{tabular}{|c|c|c|c|c|c|c|}
\hline \multirow[t]{2}{*}{$m / z$ obs } & \multirow[t]{2}{*}{$m / z \mathrm{cal}$} & \multicolumn{5}{|c|}{ Composition } \\
\hline & & HexNAc & Hex & DeoxyHex & Pent & $\mathrm{Na}$ \\
\hline 668.2396 & 668.2378 & 1 & & 2 & 1 & 1 \\
\hline 682.2558 & 682.2534 & 1 & & 3 & & 1 \\
\hline 814.2988 & 814.2957 & 1 & & 3 & 1 & 1 \\
\hline 828.3138 & 828.3113 & 1 & & 4 & & 1 \\
\hline $960.3578^{\mathrm{a}}$ & 960.3536 & 1 & & 4 & 1 & 1 \\
\hline 974.3745 & 974.3693 & 1 & & 5 & & 1 \\
\hline $1,031.3954$ & $1,031.3907$ & 2 & & 4 & & 1 \\
\hline $1,106.4177$ & $1,106.4115$ & 1 & & 5 & 1 & 1 \\
\hline $1,163.4399$ & $1,163.4330$ & 2 & & 4 & 1 & 1 \\
\hline $1,177.4550$ & $1,177.4486$ & 2 & & 5 & & 1 \\
\hline $1,238.4660$ & $1,238.4538$ & 1 & & 5 & 2 & 1 \\
\hline $1,252.4742$ & $1,252.4694$ & 1 & & 6 & 1 & 1 \\
\hline $1,268.4706$ & $1,268.4643$ & 1 & 1 & 5 & 1 & 1 \\
\hline $1,295.4867$ & $1,295.4752$ & 2 & & 4 & 2 & 1 \\
\hline $1,309.4997$ & $1,309.4909$ & 2 & & 5 & 1 & 1 \\
\hline $1,323.5140$ & $1,323.5065$ & 2 & & 6 & & 1 \\
\hline $1,325.4916$ & $1,325.4858$ & 2 & 1 & 4 & 1 & 1 \\
\hline $1,366.5244$ & $1,366.5123$ & 3 & & 4 & 1 & 1 \\
\hline $1,398.5367$ & $1,398.5273$ & 1 & & 7 & 1 & 1 \\
\hline $1,441.5433$ & $1,441.5331$ & 2 & & 5 & 2 & 1 \\
\hline $1,455.5592$ & $1,455.5488$ & 2 & & 6 & 1 & 1 \\
\hline $1,469.5767$ & $1,469.5644$ & 2 & & 7 & & 1 \\
\hline $1,471.5509$ & $1,471.5437$ & 2 & 1 & 5 & 1 & 1 \\
\hline $1,512.5827$ & $1,512.5703$ & 3 & & 5 & 1 & 1 \\
\hline $1,601.6171$ & $1,601.6067$ & 2 & & 7 & 1 & 1 \\
\hline $1,644.6239$ & $1,644.6125$ & 3 & & 5 & 2 & 1 \\
\hline $1,658.6481$ & $1,658.6282$ & 3 & & 6 & 1 & 1 \\
\hline $1,733.6598$ & $1,733.6490$ & 2 & & 7 & 2 & 1 \\
\hline $1,747.6743$ & $1,747.6646$ & 2 & & 8 & 1 & 1 \\
\hline $1,804.7018$ & $1,804.6861$ & 3 & & 7 & 1 & 1 \\
\hline $1,806.7003$ & $1,806.6653$ & 3 & 1 & 5 & 2 & 1 \\
\hline $1,865.6970$ & $1,865.6912$ & 2 & & 7 & 3 & 1 \\
\hline
\end{tabular}

Functional analysis of LPG fragments and CPI-glycan core domains

To determine the biological role(s) and relative importance of the outer branch saccharides and the CPI-GC domains in the pathogenic epithelial responses to trichomoniasis, we compared LPG and fractions released by periodate, mild acid (TFA), endo- $\beta$-galactosidase and PI-PLC (see Fig. 1) to a nontoxic biologically active dose of the proinflammatory cytokine IL-1 $\beta(25 \mathrm{ng} / \mathrm{mL})$ and to infection with live trichomonads.

The effects on epithelial cell viability following 24-h exposure to various LPG sub-domains and intact LPG were assessed as percent survival rates versus untreated cell cultures (Fig. 8). IL-8 production was measured in the cell culture supernatants in parallel to the MTT viability assays (Fig. 9). Intact LPG was nontoxic to both vaginal and endocervical epithelial cells at doses $<250 \mu \mathrm{g} / \mathrm{mL}$ and at the same time significantly increased IL- 8 production in a

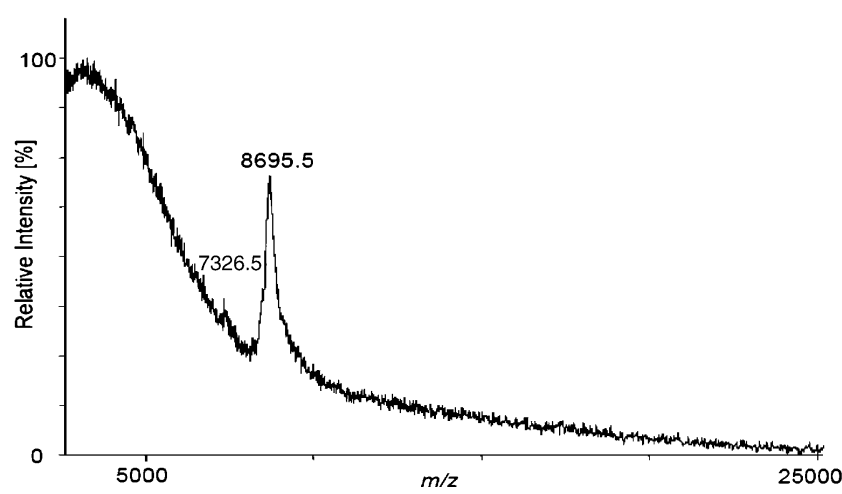

Fig. 6 MALDI-TOF mass spectrum of the CPI-GC released by mild acid treatment of the TV-LPG, plotted over the range $\mathrm{m} / \mathrm{z} 3,000$ 25,000 


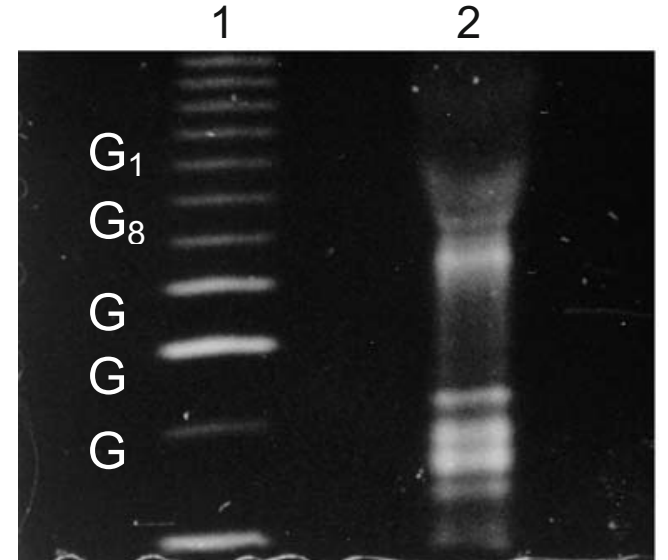

Fig. 7 FACE Analysis of endo- $\beta$-galactosidase treated CPI-GC. The CPI-GC was treated with endo- $\beta$-galactosidase for $18 \mathrm{~h}$ and the released saccharides were purified by $\mathrm{C} 18$ Sep-Pak and derivatized with ANTS for FACE analysis. Lane 1 -standard glucose oligomers; lane 2-CPI-GC digest

dose-dependent manner (Figs. 8a-b and 9a). Periodate treated LPG was nontoxic even at higher doses $(>500 \mu \mathrm{g} / \mathrm{mL})$ (Fig. 8a-b) and completely lost its proinflammatory properties (Fig. 9a). The native CPI-GC fraction was as active as intact LPG. IL-8 production was induced by nontoxic doses of LPG and CPI-GC estimated to be the equivalent of $~ 4$ 10 parasites per epithelial cell (Fig. 9a-b). In contrast, the outer branch fraction, and the PI-PLC-released saccharideI-P (see Fig. 1) were biologically inert (Figs. 8a-b and 9a). Also, inositol-P-ceramide (CPI) isolated from $T$. vaginalis (24) failed to show any biological activity (data not shown). The saccharide fraction released from native CPI-GC by endo- $\beta$-galactosidase had no biological activity but the remaining post-enzymatic CPI-GC fraction had strong proinflammatory activity (Figs. 8c and 9b). The biological specificity of this reaction was confirmed by the lack of IL-8 induction by equivalent doses of native CPI-GC from the bovine trichomonad and by the ethanol diluent (EtOH). Intact LPG and the CPI-GC fractions induced IL-8 production commensurate with that induced by a high dose recombinant IL-1 $\beta$ (Fig. 9a-b).

The intact LPG molecule and the native CPI-GC fraction induced NF- $\mathrm{KB}$ activation comparable in magnitude to that induced by estimated equivalent load of live $T$. vaginalis ( 5-10 parasites per epithelial cell) (Fig. 10a) and rapid (30-120 min) phosphorylation of NF-KB p65 subunit at Ser536 (Fig. 10b). Within $30 \mathrm{~min}$ of stimulation, the intact LPG and CPI-GC induced phosphorylation of MEK1/2 kinase (Fig. 10c) and within $1 \mathrm{~h}-\mathrm{pERK} 1 / 2$ (Fig. 10d). Levels of total ERK and MEK1/2 remained unchanged (data not shown). Neither the saccharide fractions nor the bovine CPI-GC induced MEK1/2, NF- $\mathrm{BB}$ or ERK activation (data not shown).

\section{Discussion}

This study is the first to demonstrate that $T$. vaginalis LPG contains poly- $N$-acetyllactosamine (Gal $\beta 1-4$ GlcNAc $\beta 1-3$ Gal $\beta 1-4$ GlcNAc) repeats and the first to reveal the relative biological significance of various LPG domains in triggering inflammatory cascades in vaginal epithelial cells.

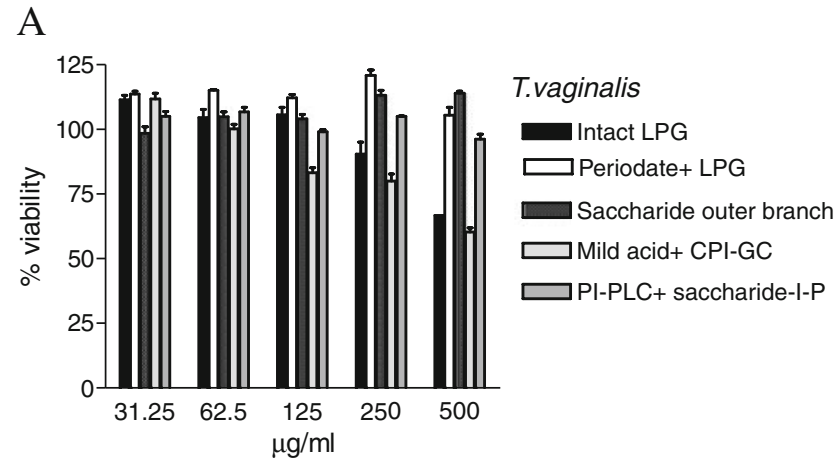

B

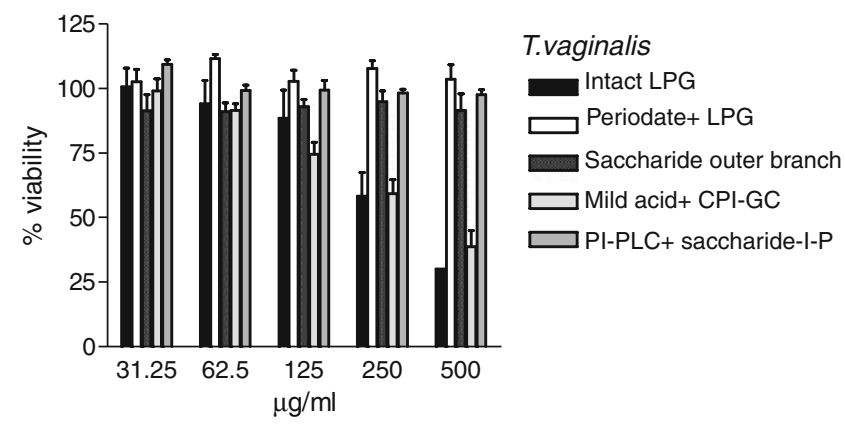

C

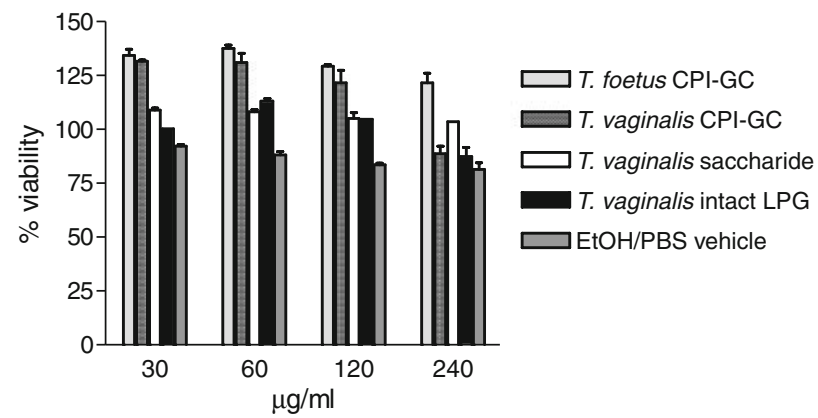

Fig. 8 Effects of LPG fractions on epithelial cell viability measured by MTT assay. Endocervical (a) and vaginal (b and c) epithelial cells were exposed for $24 \mathrm{~h}$ to intact LPG or various LPG fragments and CPI-GC obtained after treatment with periodate, mild acid (TFA) or CPI-PLC (a and $\mathbf{b}$ ). The CPI-GC and saccharide fractions shown in $\mathbf{c}$ were obtained after endo- $\beta$-galactosidase treatment of the native CPIGC. Stock solutions of lyophilized lipid fractions were prepared in $\mathrm{PBS} /$ ethanol $(\mathrm{EtOH})$ and of saccharide fractions in PBS. Recombinant human (rh) IL-1 $\beta$ served as positive control. Horizontal axes present two-fold serial dilutions of LPG and fractions at equivalent concentrations. Bars represent means and SEM from triplicate cultures in one of three independent experiments with each cell line 
Fig. 9 Dose-dependent upregulation of IL-8 after $24 \mathrm{~h}$ stimulation of vaginal epithelial cells with intact $T$. vaginalis LPG and various LPG fractions in two-fold serial dilutions. Controls included the diluents $\mathrm{PBS}$ and PBS/ethanol (EtOH), T. foetus (TF) LPG CPI-GC, live $T$. vaginalis (four to ten parasite per epithelial cell) and recombinant human IL-1 $\beta$. Bars represent the mean and SEM of duplicate cultures in one of two experiments performed with each set of fractions (a and $\mathbf{b}$ )
A

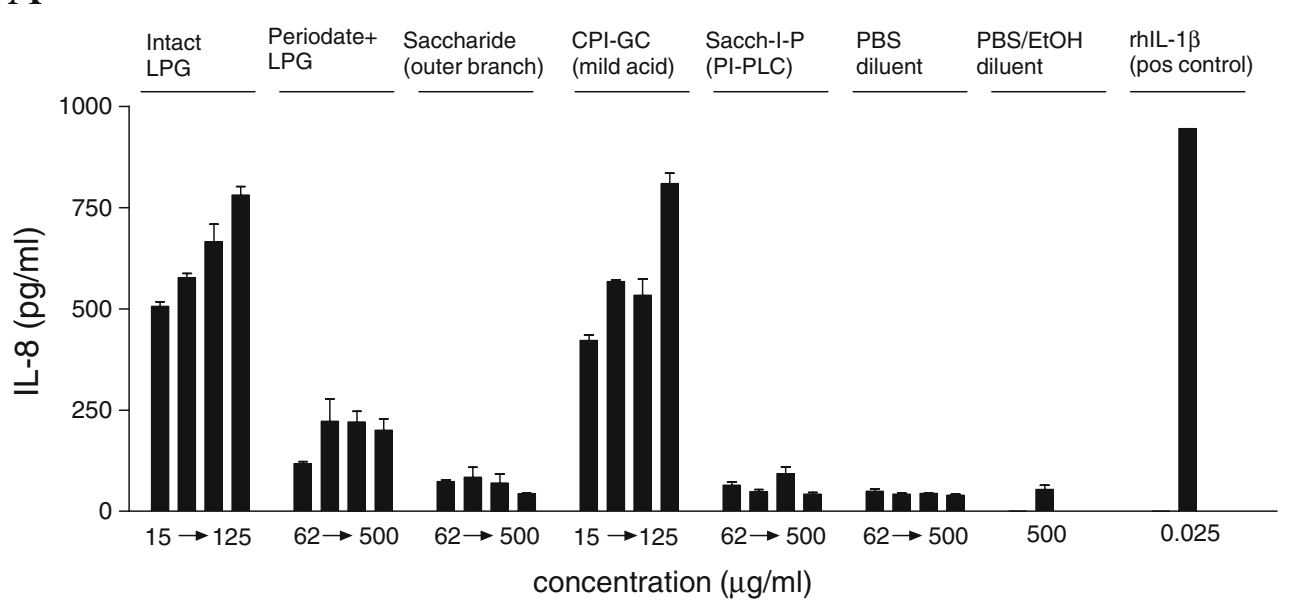

B

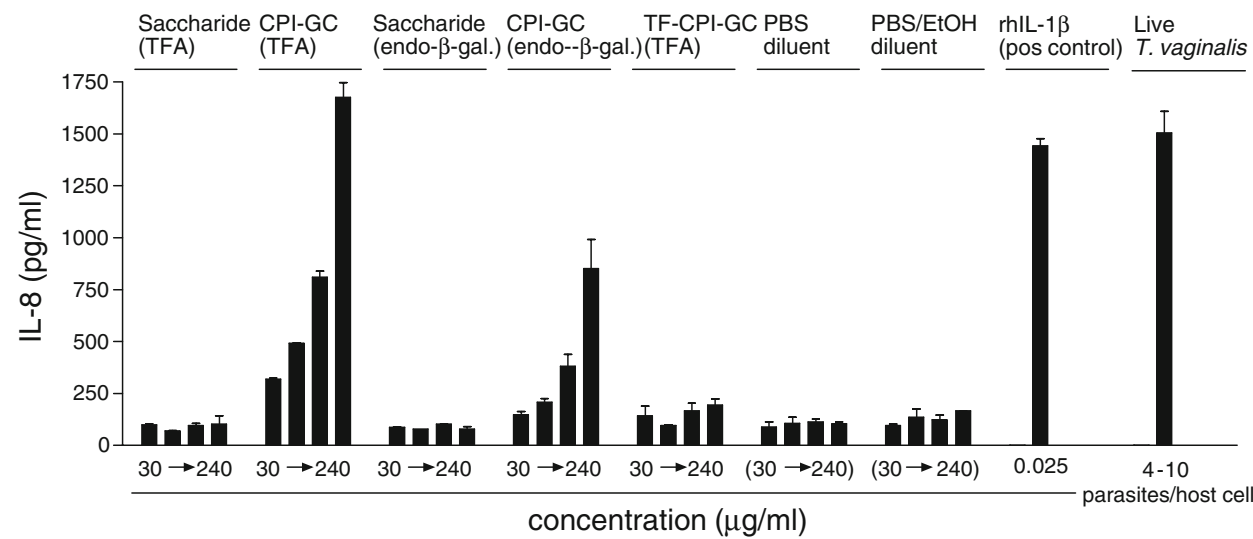

Several bioanalytical techniques such as enzymatic digestion, FACE, MS and tandem MS analyses were employed to derive the lactosamine structures in LPG and its CPI-GC core. The sensitivity of LPG and native CPI-GC to endo- $\beta$-galactosidase digestion, with the production of oligosaccharides that could be further digested with $\beta-N$ acetylhexosaminidase and $\beta$-galactosidase, was consistent with the presence of lactosamine repeats in the outer saccharide branch. Furthermore, the fragmentation patterns obtained in mass spectral analyses confirmed the results of the enzymatic digestions. The identity of terminal Gal and GlcN was derived from enzymatic, HPAE-PAD, and FACE analyses. In addition, the CPI-GC domain derived from native CPI-GC by endo- $\beta$-galactosidase treatment (see Fig. 7) may retain some of the poly- $N$-acetyllactosamine-type structures.

The poly- $N$-acetyllactosamine structures are unique in a lipid-linked phosphoinositol-anchored molecule. It is of interest to note that all reported GPI-molecules have a glycan core containing the sequence Man $\alpha 1-4 \mathrm{GlcN} \alpha 1$-Ino [49] but T. vaginalis LPG contains no Man residues. In the past, Dionex chromatographic program was used to separate monosaccharides by the PA1 column which did not adequately separate Man from Xyl and the observed peak was attributed to the presence of Man (not Xyl), since this monosaccharide would have been expected for a molecule containing a GPI anchor. However, we later determined by two different methods (GC/MS and HPAE-PAD) that LPG does not contain Man, but rather it contains Xyl [22, 27]. T. vaginalis $\mathrm{LPG}$ and its $\mathrm{CPI}-\mathrm{GC}$ appear to be unique surface glycolipids in that they express certain features of a prokaryotic glycoconjugate, e.g. large amounts of rhamnose. Even though T. vaginalis is a eukaryote, LPG is not anchored to the parasite surface by a conserved eukaryotic GPI-anchored molecule. Another important discovery is the presence of significant amounts of Rha, Gal and GlcN along with Xyl in the LPG and the CPI-GC core.

The presence of Rha and $\mathrm{Xyl}$ in each fraction (mild acid derived saccharides and CPI-GC) hindered the acquisition of glycosidase-based oligosaccharide sequence information. Rhamnosidase and xylosidase were unable to release $\mathrm{Rha} / \mathrm{Xyl}$, which suggests that the Rha and Xyl residues are not terminal and/or they do not have linkages that are susceptible to the available glycosidase enzymes. The limited ability of $\beta$-galactosidase and $\beta-N$-acetylhexosaminidase to release monosaccharides may be due to the presence of Rha and Xyl in each fraction and the presence of branches. This conclusion is supported by MS analysis, which confirmed the presence of various deoxyhexose 


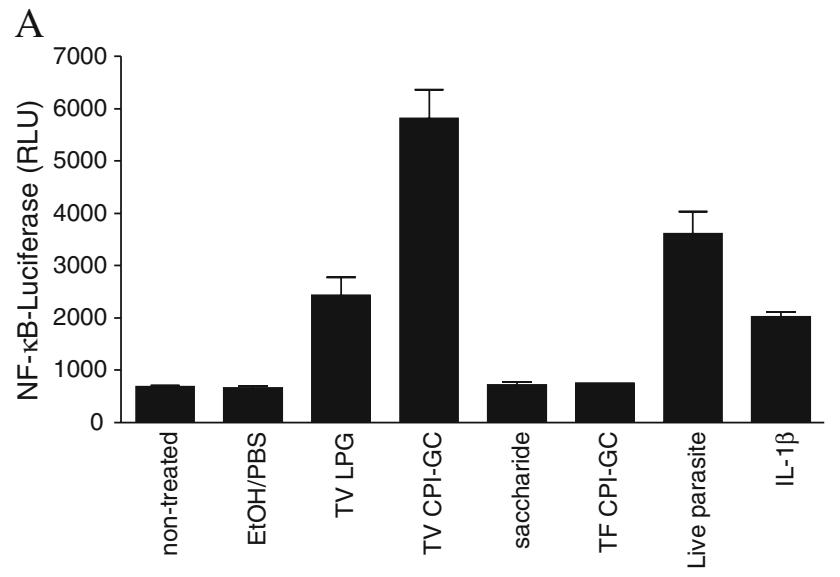

B

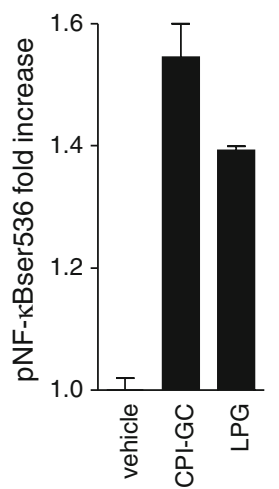

$\mathrm{C}$

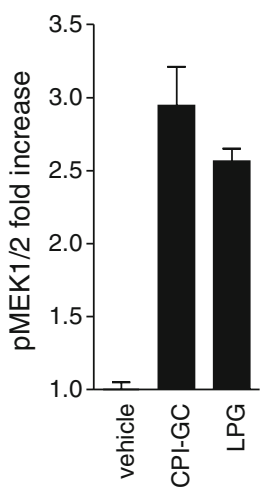

D

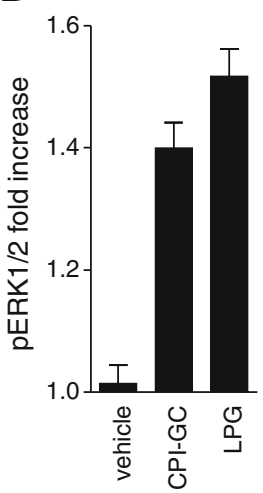

Fig. 10 Activation of NF-KB and ERK1/2 in endocervical (a) and vaginal $(\mathbf{b}-\mathbf{c})$ epithelial cells. Endocervical epithelial cell line stably transfected with pNF-kB lucifearse reporter (a) was exposed to intact TV and TF LPG, equivalent dose of native TV CPI-GC fraction and live $T$. vaginalis (four to ten parasite per epithelial cell), and rhIL-1 $\beta$ $(25 \mathrm{ng} / \mathrm{mL})$ for $24 \mathrm{~h}$. Bars represent the means and SEM of luciferase activity in relative luminescent units (RLU) measured in triplicate cultures in two experiments. Vaginal epithelial cells were assessed for pNF-kB ser536 b at $2 \mathrm{~h}, \mathrm{pMEK} 1 / 2 \mathrm{c}$ at $30 \mathrm{~min}$ and pERK $1 / 2 \mathrm{~d}$ at $1 \mathrm{~h}$ post stimulation with TV LPG or equivalent dose $(60 \mu \mathrm{g} / \mathrm{mL})$ of CPI-GC. Bars represent means + SD from triplicate cultures in two experiments

residues (Rha based on monosaccharide analysis) in the backbone of the LPG molecule and pentose branches. These residues appear to be located outside of the regions containing $N$-acetyllactosamine repeats and may block $\beta$-galactosidase and $\beta-N$-acetylhexosaminidase digestion. Determination of the detailed structures of these branched regions will require higher order MS analyses, in combination with NMR studies.

The discovery of poly- $N$-acetyllactosamine repeats in LPG and CPI-GC opens interesting possibilities for novel LPG-host interactions. For example, LPG and its CPI-GC core may serve as ligands for $\beta$-galactoside-binding lectins such as various members of the galectin family. Galectins are expressed in several cell types, including epithelial

cells, and are known to play vital roles in host-pathogen interactions and immune recognition [50-52]. In fact, our recent data suggest that galectin-1 and -3 are expressed in the human ectocervical, endocervical and vaginal epithelial cells used in our experimental systems [53].

We showed earlier that $T$. vaginalis LPG is the predominant molecule anchored to the parasite surface $[23,24]$. It is highly glycosylated, contains a lipid-linked phosphoinositol-type anchor $[22,23]$ and that it plays a significant role in the parasite adhesion and proinflammatory activation of epithelial cells originating from the three anatomic regions of the human lower female genital tractendocervical, ectocervical and vaginal [22]. We showed that LPG induced a marked dose-dependent upregulation of the chemokines IL- 8 and MIP- $3 \alpha$ and a moderate increase of the cytokine IL- 6 in a dose-dependent and speciesspecific manner, whereas IL-1 $\beta$ and TNF $\alpha$ levels in the same cultures remained at baseline. It is important to note that these cells are deficient in the molecular machinery for bacterial endotoxin responses [37], which, along with the lack of bacterial contamination confirmed by endotoxinnegative testing of the purified LPG and fractions, suggests specific novel pathways of LPG signaling different from that utilized by bacterial LPS.

The results presented here clearly demonstrate a key role for the CPI-GC core of LPG in triggering inflammatory cascades in cervicovaginal epithelial cells. Importantly, LPG from the bovine parasite $T$. foetus showed no effect on cytokine production; this result demonstrates the species specificity of the cytokine and chemokine triggering mechanisms. Clearly, both the intact and the endo- $\beta$-galactosidase treated CPI-GC moiety from $T$. vaginalis are capable of activation of the major proinflammatory nuclear transcription factor NF-KB and production of IL-8. No other saccharide fraction had this effect. Multiple proinflammatory stimuli, e.g. endogenous cytokines, bacterial, viral and eukaryotic pathogens, activate NF-kB via a series of phosphorylation events. These events include its dissociation from the cytoplasmic inhibitor IKB and translocation to the nucleus, where NF-kB cooperates with other factors to transactivate a myriad of proinflammatory genes including IL-8 [54]. IL-8 is the most powerful chemoattractant for neutrophils and macrophages and its presence in the vaginal discharge is indicative of acute and chronic inflammatory conditions of the lower female genital tract [55-57]. In addition, IL-8 may be directly linked to increased HIV-1 replication and transmission in the genital tract mucosa $[58,59]$ and thus represents one possible mechanism for the increased HIV transmission incidence in women with trichomoniasis.

LPG and CPI-GC elicited phosphorylation of the NF- $\mathrm{KB}$ p65 subunit at Ser536. This phosphorylation event occurs after NF- $\mathrm{kB}$ dissociation from its cytoplasmic inhibitor IKB 
and serves to slow down its export from the nucleus back to the cytosol, thus increasing the amplitude of NF-kBinduced gene transactivation. Ser536 phosphorylation also promotes NF- $\mathrm{kB}$ mediated transcription via recruitment of other transcription coactivators such as $\mathrm{p} 300$, enlarging the scope of proinflammatory activities [60]. LPG and CPI-GC also induced phosphorylation of ERK1/2, which is activated in macrophages upon trichomonad infection and linked to host cell apoptosis [61]. This is consistent with our findings that CPI-GC core (and not the outer branch saccharides) is responsible for the reduction of human vaginal and cervical cell viability.

Here we also demonstrate for the first time that $T$. vaginalis LPG signaling may be mediated by MEK1/2 phosphorylation. MEK $1 / 2$ has been implicated in the activation of the ERK family of protein kinases [62] and thus these data are in agreement with the downstream activation of ERK1/2 observed in response to LPG and CPI-GC.

\section{Conclusions}

The results presented in this paper suggest that, similar to the lipid A of LPS from Gram negative bacteria, the CPI-GC moiety of $T$. vaginalis LPG is important in regulating the host inflammatory response. In the context of normal human cervicovaginal epithelial cells, the immunoinflammatory activation appears to occur in the absence of the dominant LPS-responsive molecular machinery, including TLR4, MD2 and CD14. The loss of proinflammatory activity following periodate and PI-PLC treatments of LPG suggests the importance of both the lipid and glycan components of the CPI-GC in epithelial cell receptor binding initiating signaling cascades and downstream pathogenic responses. While the host receptors for any of the T. vaginalis surface structures are still unknown, the discovery of poly- $\mathrm{N}$ acetyllactosamine repeats in LPG and CPI-GC opens the possibilities for interaction with the host galactoside binding lectins. Studies on pattern recognition receptors for LPG and its CPI-GC are underway to further define the role of T. vaginalis in mucosal immune regulation.

Acknowledgements This work was supported by grants from the US NIH National Institute of Child Health and Human Development R21HD054451 (RNF) and the NIH National Center for Research Resources P41 RR010888 and S10 RR015942 (CEC). The authors thank J. F Cipollo for assistance with the LC/MS/MS analyses. Dr. B. N. Singh, Dr. C. E. Costello and Dr. R. Fichorova have equal contributions to this manuscript.

Open Access This article is distributed under the terms of the Creative Commons Attribution Noncommercial License which permits any noncommercial use, distribution, and reproduction in any medium, provided the original author(s) and source are credited.

\section{References}

1. Petrin, D., Delgaty, K., Bhatt, R., Garber, G.: Clinical and microbiological aspects of Trichomonas vaginalis. Clin. Microbiol. Rev. 11, 300-317 (1998)

2. Ryu, J.S., Min, D.Y.: Trichomonas vaginalis and trichomoniasis in the Republic of Korea. Korean J. Parasitol. 44, 101-116 (2006)

3. Schwebke, J.R.: Trichomoniasis in adolescents: a marker for the lack of a public health response to the epidemic of sexually transmitted diseases in the United States. J. Infect. Dis. 192, 2036-2038 (2005)

4. Schwebke, J.R., Burgess, D.: Trichomoniasis. Clin. Microbiol. Rev. 17, 794-803 (2004)

5. Schwebke, J.R., Aira, T., Jordan, N., Jolly, P.E., Vermund, S.H.: Sexually transmitted diseases in Ulaanbaatar, Mongolia. Int. J. STD. AIDS. 9, 354-358 (1998)

6. Bowden, F.J., Paterson, B.A., Mein, J., Savage, J., Fairley, C.K., Garland, S.M., Tabrizi, S.N.: Estimating the prevalence of Trichomonas vaginalis, Chlamydia trachomatis, Neisseria gonorrhoeae, and human papillomavirus infection in indigenous women in northern Australia. Sex Transm. Infect. 75, 431-434 (1999)

7. Gilbert, R.O., Elia, G., Beach, D.H., Klaessig, S., Singh, B.N.: Cytopathogenic effect of Trichomonas vaginalis on human vaginal epithelial cells cultured in vitro. Infect. Immun. 68, 4200-4206 (2000)

8. Sommer, U., Costello, C.E., Hayes, G.R., Beach, D.H., Gilbert, R.O., Lucas, J.J., Singh, B.N.: Identification of Trichomonas vaginalis cysteine proteases that induce apoptosis in human vaginal epithelial cells. J. Biol. Chem. 280, 23853-23860 (2005)

9. Krieger, J.N., Jenny, C., Verdon, M., Siegel, N., Springwater, R., Critchlow, C.W., Holmes, K.K.: Clinical manifestations of trichomoniasis in men. Ann. Internal. Med. 118, 844-849 (1993)

10. Krieger, J.N., Verdon, M., Siegel, N., Holmes, K.K.: Natural history of urogenital trichomoniasis in men. J. Urol. 149, 14551458 (1993)

11. Sorvillo, F., Smith, L., Kerndt, P., Ash, L.: Trichomonas vaginalis, HIV, and African-Americans. Emerg. Infect. Dis. 7, 927-932 (2001)

12. Weinstock, H., Berman, S., Cates Jr., W.: Sexually transmitted diseases among American youth: incidence and prevalence estimates, 2000. Perspect. Sex Reprod. Health. 36, 6-10 (2004)

13. McClelland, R.S., Sangare, L., Hassan, W.M., Lavreys, L., Mandaliya, K., Kiarie, J., Ndinya-Achola, J., Jaoko, W., Baeten, J.M.: Infection with Trichomonas vaginalis increases the risk of HIV-1 acquisition. J. Infect. Dis. 195, 698-702 (2007)

14. Corbeil, L.B., Campero, C.M., Rhyan, J.C., BonDurant, R.H.: Vaccines against sexually transmitted diseases. Reprod. Biol. Endocrinol. 1, 118 (2003)

15. Ryu, J.S., Kang, J.H., Jung, S.Y., Shin, M.H., Kim, J.M., Park, H., Min, D.Y.: Production of interleukin-8 by human neutrophils stimulated with Trichomonas vaginalis. Infect. Immun. 72, 13261332 (2004)

16. Shaio, M.F., Lin, P.R., Liu, J.Y., Yang, K.D.: Generation of interleukin-8 from human monocytes in response to Trichomonas vaginalis stimulation. Infect. Immun. 63, 3864-3870 (1995)

17. Ferguson, M.A.: The structure, biosynthesis and functions of glycosylphosphatidylinositol anchors, and the contributions of trypanosome research. J. Cell Sci. 112(Pt 17), 2799-2809 (1999)

18. Turco, S.J., Descoteaux, A.: The lipophosphoglycan of Leishmania parasites. Annu. Rev. Microbiol. 46, 65-94 (1992)

19. Soares, R.P.P., Cardoso, T.L., Barron, T., Araujo, M.S.S., Pimenta, P.F.P., Turco, S.J.: Leishmania braziliensis: a novel mechanism in the lipophosphoglycan regulation during metacyclogenesis. Int. J. Parasitol. 35, 245-253 (2005) 
20. Lodge, R., Descoteaux, A.: Modulation of phagolysosome biogenesis by the lipophosphoglycan of Leishmania. Clinical Immunology 114, 256-265 (2005)

21. Singh, B.N., Lucas, J.J., Beach, D.H., Shin, S.T., Gilbert, R.O.: Adhesion of Trichomonas foetus to bovine vaginal epithelial cells. Infect. Immun. 67, 3847-3854 (1999)

22. Fichorova, R.N., Trifonova, R.T., Gilbert, R.O., Costello, C.E., Hayes, G.R., Lucas, J.J., Singh, B.N.: Trichomonas vaginalis lipophosphoglycan triggers a selective upregulation of cytokines by human female reproductive tract epithelial cells. Infect. Immun. 74, 5773-5779 (2006)

23. Singh, B.N.: Lipophosphoglycan-like glycoconjugate of Trichomonas foetus and Trichomonas vaginalis. Mol. Biochem. Parasitol. 57, 281294 (1993)

24. Singh, B.N., Beach, D.H., Lindmark, D.G., Costello, C.E.: Identification of the lipid moiety and further characterization of the novel lipophosphoglycan-like glycoconjugates of Trichomonas vaginalis and Trichomonas foetus. Arch. Biochem. Biophys. 309, 273-280 (1994)

25. Singh, B.N., Lucas, J.J., Fichorova, R.N.: In: Khan, N.A., Jarrol, E.L. (eds.) Emerging Protozoan Pathogens, pp. 411-455. Taylor \& Francis, London (2007)

26. Guha-Niyogi, A., Sullivan, D.R., Turco, S.J.: Glycoconjugate structures of parasitic protozoa. Glycobiology. 11, 45R-59R (2001)

27. Singh, B.N., BonDurant, R.H., Campero, C.M., Corbeil, L.B.: Immunological and biochemical analysis of glycosylated surface antigens and lipophosphoglycan of Trichomonas foetus. J. Parasitol. 87, 770-777 (2001)

28. Bastida-Corcuera, F.D., Okumura, C.Y., Colocoussi, A., Johnson, P.J.: Trichomonas vaginalis lipophosphoglycan mutants have reduced adherence and cytotoxicity to human ectocervical cells. Eukaryot. Cell. 4, 1951-1958 (2005)

29. Hashimoto, W., Miyake, O., Nankai, H., Murata, K.: Molecular identification of an alpha-L-rhamnosidase from Bacillus sp strain GL1 as an enzyme involved in complete metabolism of gellan. Arch. Biochem. Biophys. 415, 235-244 (2003)

30. Jordan, D.B., Braker, J.D.: Inhibition of the two-subsite beta-Dxylosidase from Selenomonas ruminantium by sugars: competitive, noncompetitive, double binding, and slow binding modes. Arch. Biochem. Biophys. 465, 231-246 (2007)

31. Viseux, N., Costello, C.E., Domon, B.: Post-source decay mass spectrometry: optimized calibration procedure and structural characterization of permethylated oligosaccharides. J. Mass Spectrom. 34, 364-376 (1999)

32. Costello, C.E., Contado-Miller, J.M., Cipollo, J.F.: A glycomics platform for the analysis of permethylated oligosaccharide alditols. J. Am. Soc. Mass Spectrom. 18, 1799-1812 (2007)

33. Fichorova, R.N., Rheinwald, J.G., Anderson, D.J.: Generation of papillomavirus-immortalized cell lines from normal human ectocervical, endocervical, and vaginal epithelium that maintain expression of tissue-specific differentiation proteins. Biol. Reprod. 57, 847-855 (1997)

34. Fichorova, R.N., Zhou, F., Ratnam, V., Atanassova, V., Jiang, S., Strick, N., Neurath, A.R.: Anti-human immunodeficiency virus type 1 microbicide cellulose acetate 1,2-benzenedicarboxylate in a human in vitro model of vaginal inflammation. Antimicrob. Agents Chemother. 49, 323-335 (2005)

35. Fichorova, R.N., Bajpai, M., Chandra, N., Hsiu, J.G., Spangler, M., Ratnam, V., Doncel, G.F.: Interleukin (IL)-1, IL-6, and IL-8 predict mucosal toxicity of vaginal microbicidal contraceptives. Biol. Reprod. 71, 761-769 (2004)

36. Doncel, G.F., Chandra, N., Fichorova, R.N.: Preclinical assessment of the proinflammatory potential of microbicide candidates. J. Acquir. Immune. Defic. Syndr. 37(Suppl 3), S174-180 (2004)
37. Fichorova, R.N., Cronin, A.O., Lien, E., Anderson, D.J., Ingalls, R.R.: Response to Neisseria gonorrhoeae by cervicovaginal epithelial cells occurs in the absence of toll-like receptor 4-mediated signaling. J. Immunol. 168, 2424-2432 (2002)

38. Fichorova, R.N., Tucker, L.D., Anderson, D.J.: The molecular basis of nonoxynol-9-induced vaginal inflammation and its possible relevance to human immunodeficiency virus type 1 transmission. J. Infect. Dis. 184, 418-428 (2001)

39. Fichorova, R.N., Desai, P.J., Gibson 3rd, F.C., Genco, C.A.: Distinct proinflammatory host responses to Neisseria gonorrhoeae infection in immortalized human cervical and vaginal epithelial cells. Infect. Immun. 69, 5840-5848 (2001)

40. Fichorova, R.N., Anderson, D.J.: Differential expression of immunobiological mediators by immortalized human cervical and vaginal epithelial cells. Biol. Reprod. 60, 508-514 (1999)

41. Krebs, F.C., Miller, S.R., Catalone, B.J., Fichorova, R., Anderson, D., Malamud, D., Howett, M.K., Wigdahl, B.: Comparative in vitro sensitivities of human immune cell lines, vaginal and cervical epithelial cell lines, and primary cells to candidate microbicides nonoxynol 9, C31G, and sodium dodecyl sulfate. Antimicrob. Agents Chemother. 46, 2292-2298 (2002)

42. Wu, Z.W., Chen, Z.W., Phillips, D.M.: Human genital epithelial cells capture cell-free human immunodeficiency virus type 1 and transmit the virus to CD4(+) cells: implications for mechanisms of sexual transmission. J. Infect. Dis. 188, 1473-1482 (2003)

43. Steele, C., Fidel Jr., P.L.: Cytokine and chemokine production by human oral and vaginal epithelial cells in response to Candida albicans. Infect. Immun. 70, 577-583 (2002)

44. Barousse, M.M., Steele, C., Dunlap, K., Espinosa, T., Boikov, D., Sobel, J.D., Fidel, P.L.: Growth inhibition of Candida albicans by human vaginal epithelial cells. J. Infect. Dis. 184, 1489-1493 (2001)

45. Levin, J., Bang, F.B.: Clottable protein in Limulus; its localization and kinetics of its coagulation by endotoxin. Thromb. Diath. Haemorrh. 19, 186-197 (1968)

46. Trifonova, R.T., Pasicznyk, J.M., Fichorova, R.N.: Biocompatibility of solid-dosage forms of anti-human immunodeficiency virus type 1 microbicides with the human cervicovaginal mucosa modeled ex vivo. Antimicrob. Agents Chemother. 50, 4005-4010 (2006)

47. Singh, B.N., Lucas, J.J., Beach, D.H., Costello, C.E.: Expression of a novel cell surface lipophosphoglycan-like glycoconjugate in Trypanosoma cruzi epimastigotes. J. Biol. Chem. 269, 2197221982 (1994)

48. Reinhold, V.N., Reinhold, B.B., Costello, C.E.: Carbohydrate molecular weight profiling, sequence, linkage, and branching data: ES-MS and CID. Anal. Chem. 67, 1772-1784 (1995)

49. Orlean, P., Menon, A.K.: Thematic review series:lipid posttranslational modifications. GPI anchoring of protein in yeast and mammalian cells, or: how we learned to stop worrying and love glycophospholipids. J. Lipid Res. 48, 993-1011 (2007)

50. Rabinovich, G.A., Gruppi, A.: Galectins as immunoregulators during infectious processes: from microbial invasion to the resolution of the disease. Parasite. Immunol. 27, 103-114 (2005)

51. Ilarregui, J.M., Bianco, G.A., Toscano, M.A., Rabinovich, G.A.: The coming of age of galectins as immunomodulatory agents: impact of these carbohydrate binding proteins in T cell physiology and chronic inflammatory disorders. Ann. Rheum. Dis. 64, 96-103 (2005)

52. van den Berg, T.K., Honing, H., Franke, N., van Remoortere, A., Schiphorst, W.E., Liu, F.T., Deelder, A.M., Cummings, R.D., Hokke, C.H., van Die, I.: LacdiNAc-glycans constitute a parasite pattern for galectin-3-mediated immune recognition. J. Immunol. 173, 1902-1907 (2004)

53. Fichorova, R.N., Trifonova, R.T., Singh, B.N.: T. vaginalis LPG regulates cytokine responses via binding galectins on human vaginal epithelial cells. Microbicides 2008. New Delhi, India, 2008 
54. Perkins, N.D.: Achieving transcriptional specificity with NF-kB. Int. J. Biochem. Cell Biol. 29, 1433-1448 (1997)

55. Fichorova, R.N.: Guiding the vaginal microbicide trials with biomarkers of inflammation. J. Acquir. Immune. Defic. Syndr. 37 (Suppl 3), S184-193 (2004)

56. Cauci, S., Guaschino, S., De Aloysio, D., Driussi, S., De Santo, D., Penacchioni, P., Quadrifoglio, F.: Interrelationships of interleukin8 with interleukin-1beta and neutrophils in vaginal fluid of healthy and bacterial vaginosis positive women. Mol. Hum. Reprod. 9, 5358 (2003)

57. Mukaida, N.: Interleukin-8: an expanding universe beyond neutrophil chemotaxis and activation. Int. J. Hematol. 72, 391$398(2000)$

58. Narimatsu, R., Wolday, D., Patterson, B.K.: IL-8 increases transmission of HIV type 1 in cervical explant tissue. AIDS Res. Hum. Retroviruses. 21, 228-233 (2005)
59. Lane, B.R., Lore, K., Bock, P.J., Andersson, J., Coffey, M.J., Strieter, R.M., Markovitz, D.M.: Interleukin-8 stimulates human immunodeficiency virus type 1 replication and is a potential new target for antiretroviral therapy. J. Virol. 75, 8195-8202 (2001)

60. Oh, S.-M., Lee, S.-H., Lee, B.-J., Pyo, C.-W., Yoo, N.-K., Lee, S.Y., Kim, J., Choi, S.-Y.: A distinct role of neutrophil lactoferrin in RelA/p65 phosphorylation on Ser536 by recruiting TNF receptorassociated factors to I\{kappa\}B kinase signaling complex. J. Immunol. 179, 5686-5692 (2007)

61. Ryang, Y.S., Chang, J.H., Park, J.Y.: Involvement of MAP kinases in apoptosis of macrophage treated with Trichomonas vaginalis. Yonsei. Med. J. 45, 751-754 (2004)

62. Crews, C.M., Alessandrini, A., Erikson, R.L.: The primary structure of MEK, a protein kinase that phosphorylates the ERK gene product. Science 258, 478-480 (1992) 